\title{
Työkonerenkaiden ominaisuudet ja maan rakenteen säilyttäminen
}

\author{
Juhani Kurjenluoma ${ }^{1)}$, Jukka Ahokas ${ }^{1)}$, Laura Alakukku ${ }^{2)}$ \\ ${ }^{1)}$ Helsingin yliopisto, maa- ja kotitalousteknologian laitos, 00014 Helsingin yliopisto, PL 27 \\ Latokartanonkaari 13,juhani.kurjenluoma@helsinki.fi,jukka.ahokas@helsinki.fi \\ ${ }^{2)}$ Maa- ja elintarviketalouden tutkimuskeskus, Maaperä ja ympäristö, 31600 Jokioinen, \\ laura.alakukku@mtt.fi
}

\section{Johdanto}

Suurten koneiden massa ja rengaspaine voivat aiheuttaa maan tiivistymistä sekä muokkauskerroksessa että sen alapuolella olevassa pohjamaassa. Tiivistymisriski on suurin, kun maa on märkää. Tiivistyminen huonontaa maan viljelyominaisuuksia, alentaa satoa ja lisää ympäristökuormitusta. Maan rakenteeseen vaikuttavat sen ominaisuuksien ja yksittäisten koneiden ohella käytettävät työmenetelmät ja koneketjut sekä töiden ajoitus.

Työkonekäyttöön suunnitellut renkaat ovat pääsääntöisesti ristikudosrakenteisia ja niissä käytettävä rengaspaine on 200-400 kPa. Raskaimmissa työkoneissa, karjanlannan- ja kalkinlevittimissä sekä rehu- ja perävaunuissa, joiden kokonaismassa voi olla yli $30 \mathrm{Mg}$, käytetään varsin yleisesti myös kuorma-autojen ja erikoiskoneiden renkaita. Niiden kantavuus on suuri ja ne soveltuvat hyvin maantieajoon suurella ajonopeudella. Pienen pintapaineen, hyvän kulutuskestävyyden ja hyvien kulkuominaisuuksiensa vuoksi vyörenkaiden käyttö on yleistynyt raskaissa maatalouskoneisssa vaikka ne ovat ristikudosrenkaita kalliimpia.

Korkea rengaspaine ja jäykkärakenteinen rengas välittävät suuren pintapaineen maahan. Yhdistettynä suureen rengaskuormaan ja märkiin ajo-olosuhteisiin pintapaine voi tiivistää maata tavanomaista muokkauskerrosta syvemmältä. Suuren massan, jo $3 \mathrm{Mg}$ akselikuorman, tiivistävä vaikutus näkyy maan kosteudesta ja eristä muista ominaisuuksista riippuen myös muokkauskerroksen alapuolella . Pohjamaan tiivistymisen vaikutukset voivat olla pitkäaikaisia ja toistuva kuormitus pitää maan tiiviinä. Alakukkun (2000) mukaan savimaan tiivistyminen puolen metrin syvyyteen pienensi viljasatoa keskimäärin $2 \% 17$ jälkivaikutusvuoden aikana.

Maan tiivistymisriskiä voidaan vähentää minimoimalla peltoliikenne maan ollessa märkää sekä käyttämällä olosuhteisiin parhaiten soveltuvaa teknologiaa ja rengasvarustusta. Maassa tapahtuvien muutosten ennakointi vaurioiden välttämiseksi edellyttää eri tyyppisten renkaiden tiivistämisominaisuuksien ja maan tiivistymisherkkyden tuntemista. Tijink et. al (1995) mukaan alhaisen pintapaineen omaavien renkaiden käyttö on tärkein keino vähentää maan haitallista tiivistymistä. Käyttämällä pehmeitä ja elastisia renkaita tai teloja voidaan käyttää suurempiakin pyöräkuormia tiivistämättä pohjamaata, joskin märissä olosuhteissa yli $40-50 \mathrm{kN}$ pyörä- tai telakuormilla ei pohjamaan tiivistymiseltä voida välttyä (van der Akker, 2003). Tämän tutkimuksen tavoite on selvittää rakenteeltan eri tyyppisten työkonerenkaiden käyttöominaisuuksien eroja sekä renkaiden vaikutusta maan rakenteeseen.

\section{Aineistot ja menetelmät}

Tutkimuksessa verrattiin viiden työkonekäyttöön tarkoitetun renkaan ominaisuuksia ja niiden vaikutusta maan rakenteeseen. Renkaiden tekniset ominaisuudet ja tutkimuksessa käytetty rengaspaineet ovat taulukossa 1. Rengaspaineina käytettiin valmistajan, valitulle kuormalle pelto- ja maantieajoon suosittelemaa painetta. Kaikien rengaiden rengaskuorma oli kokeissa 3110 kg.

Taulukko 1. Vertailtavien renkaiden tekniset ominaisuudet ja tutkimuksessa käytetty rengaspaine.

\begin{tabular}{|l|l|l|l|l|l|l|}
\hline Rengas & Koko & Kudos- & Ulkohal- & \multicolumn{2}{|l|}{ Renkaan } & \multicolumn{2}{|l|}{ Renkaiden ilmanpaineet $(\mathrm{kPa})$} \\
& & rakenne & halkaisija $(\mathrm{mm})$ & leveys $(\mathrm{mm})$ & pelto & tie $\left(40 \mathrm{~km} \mathrm{~h}^{-1}\right)$ \\
\hline $\mathrm{Av}$ & $600 / 55 \mathrm{R} 26,5$ & vyö & 1332 & 604 & 120 & 200 \\
\hline $\mathrm{Bv}$ & $600 / 55 \mathrm{R} 26,5$ & vyö & 1360 & 618 & 140 & 180 \\
\hline $\mathrm{Cv}$ & $600 / 55 \mathrm{R} 26,5$ & vyö & 1344 & 662 & 100 & 150 \\
\hline $\mathrm{Dr}$ & $600 / 55-26,5$ & ristik. & 1348 & 617 & 150 & 200 \\
\hline $\mathrm{Er}$ & $600 / 55-26,5$ & ristik & 1355 & 614 & 120 & 200 \\
\hline
\end{tabular}


Vertailukokeet tehtiin MTT/Vakolan pellolla Vihdissä kevätkesällä 2003, jolloin maa oli syvältä märkää. Koelohko oli syksyllä kynnettyllä hiesusavimaalla, joka äestettiin ennen koekeita 4-8 cm:n syvyyteen.

Koetta varten lohko jaettiin 6,5 m:n ajokaistoihin, jolloin voitiin aina ajaa tallaamatonta uraa. Maan mittaukset tehtiin ajokaistojen suhteen poikittaisten, kolmen mittalinjan kohdalta. Ajojärjestys arvottiin ja yhdellä koejäsenellä tehtiin mittauksia joko meno- ja paluukaistalla tai vain yhteen suuntaan.

Vertailtavia renkaiden ominaisuuksia olivat vetovastus ja renkaan maahan tekemän uran syvyys. Mittauksen aikana perävaunun renkaat tekivät oman uran eivätkä kulkeneet traktorin renkaiden jättämässä polanteessa. Vetovoima, ajonopeus ja urasyvyys rekisterötiin määrämatkoilta mitattujen yksittäisten mittausten keskiarvona. Pellon kaltevuudesta aiheutuva rinnevastus mitattiin kallistuma-anturin avulla. Ajonopeuden mittauksessa hyödynnettiin Valmet 805 autocontrol traktorin Dickey-john RVSII maatutkaa . Urasyvyys määritettiin mittaamalla kahden vierekkäisen kulkeneen, toisiinsa kytkemätömien pyörien korkeusero Banner U-GAGE S18U ultraäänianturilla.

Peltoajon vaikutus maahan määritettiin mittaamalla maan kartio-indeksi ja maan koheesio sekä mitattiin maan kosteus. Kartio-indeksi määritettiin ASAE S313 standardin mukaisesti mittaamalla kartion tunkeumapaine eli cone-indeksi (MPa). Mittalaitteena käytettiin mittaustulokset tallentavaa Eijkelkamp 06.15 penetrometriä. Maahiukkasten välistä koheesiota ja siinä tallauksen seurauksena tapahtuvia muutoksia mitattiin Geonor H-60 siipikairan avulla. Maan kosteus mitattiin Decacon ECH2O maassa olevan maaveden dielektisyysominaisuuksiin perustuvalla mittarilla.

Tässä raportissa esitetyt tulokset ovat kolmessa kokeessa suoritettujen mittausten keskiarvoja.

\section{Tulokset ja tulosten tarkastelu Renkaiden vetovastus ja urat}

Vetovastuskokeissa syntyi eroja vertailurenkaiden välille sekä rengaskohtaisesti eri paineita käytettäessä että kudosrakenteen suhteen (kuva 1 ). Vyörenkaiden vetovastus oli pelto- ja tiepaineiden keskiarvoista laskien n. 25\% pienempi kuin ristikudosrenkaiden.

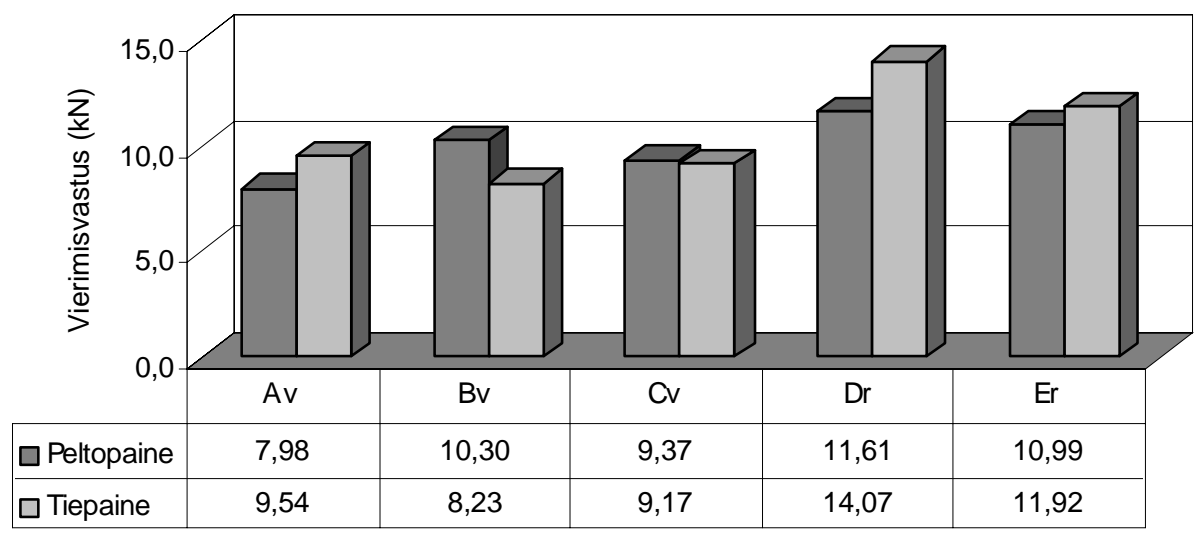

Kuva 1. Vertailurenkaiden keskimääräinen vetovastus pelto- ja tiepaineita käytettäsessä

Renkaista peltoon jääneet urat kuvaavat maan tallautumista ja siihen vaikuttavat paitsi rengaspaine myös renkaan rakenne ja elastisuus sekä maan ja renkaan välisen kosketuspinnan ala. Syvimmät ja matalimmat urat synnytti ristikudosrengas Dr, jolla myös rengaspaineen aiheuttama urasyvyyden kasvu oli vertailun suurin (kuva 2). Pienin muutos oli hyvin elastisella ja maan pinnanmuotoihin mukautuvalla renkaalla Av. Kokeen aikana tehtyjen havaintojen perusteella voitiin todeta urasyvyyteen vaikuttaviksi tekijöiksi aikaisemmin mainittujen lisäksi renkaan kosketuspinnan poikkileikkauksen pyöreys ja sen leveys. Tämä käy ilmi verrattaessa renkaiden Cv ja Dr tuloksia keskenään. 


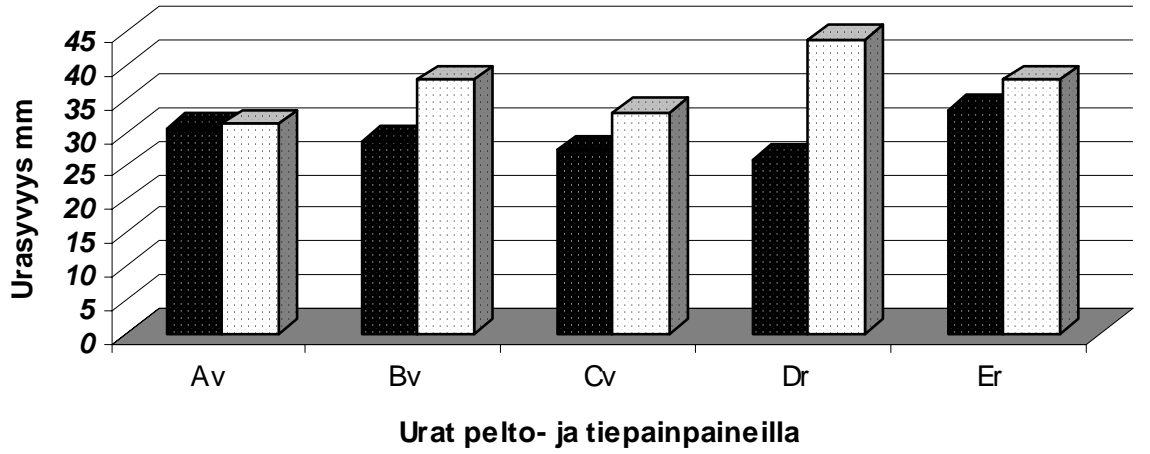

Kuva 2. Vertailurenkaiden aiheuttamat urat pellossa.

\section{Renkaan vaikutus maahan}

Cone indeksi (CI) ja siipikairamittaukset tehtiin sekä renkaan jäljestä keskeltä että jäljen vierestä, häiriintymättömästä maasta. Mittaukset tehtiin 2-3 eri syvyydestä. Jäljestä ja vierestä saatujen tulosten ero kuvaa renkaiden aiheuttamaa muutosta maassa (kuva 3, kuva 4 ja kuva 5).

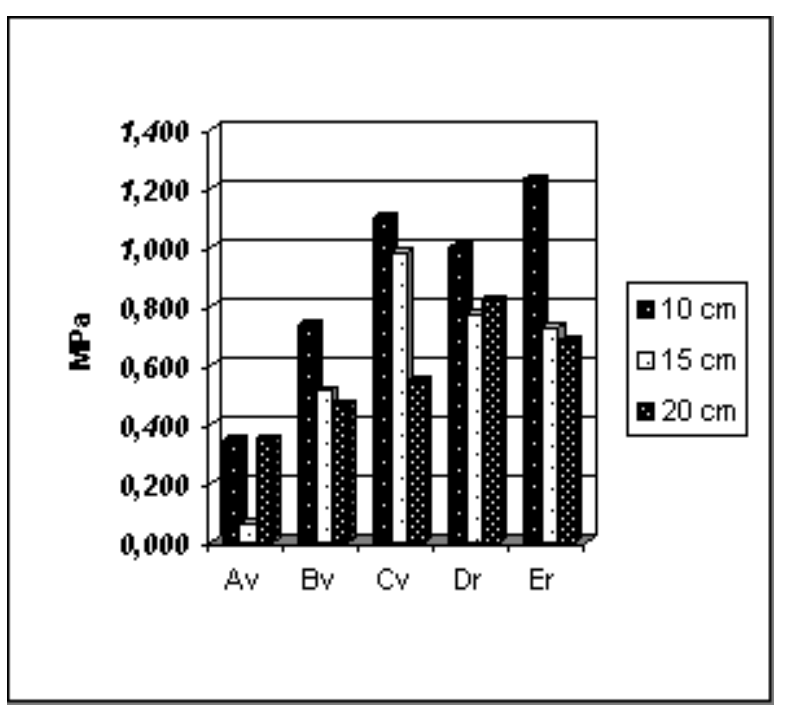

Kuva 3. CI muutos peltopaineilla ajettaessa

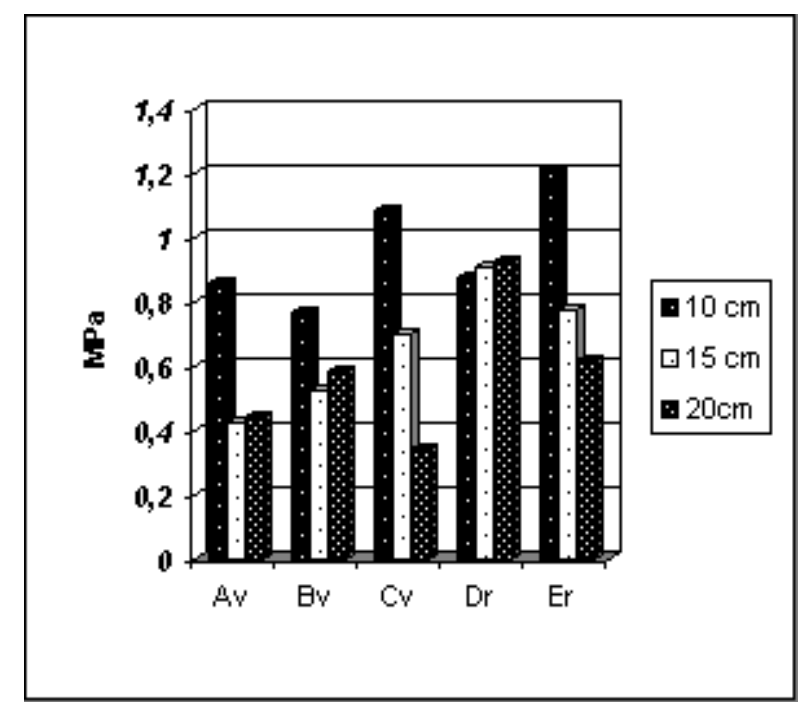

Kuva 4. CI muutos tiepaineilla ajettaessa.

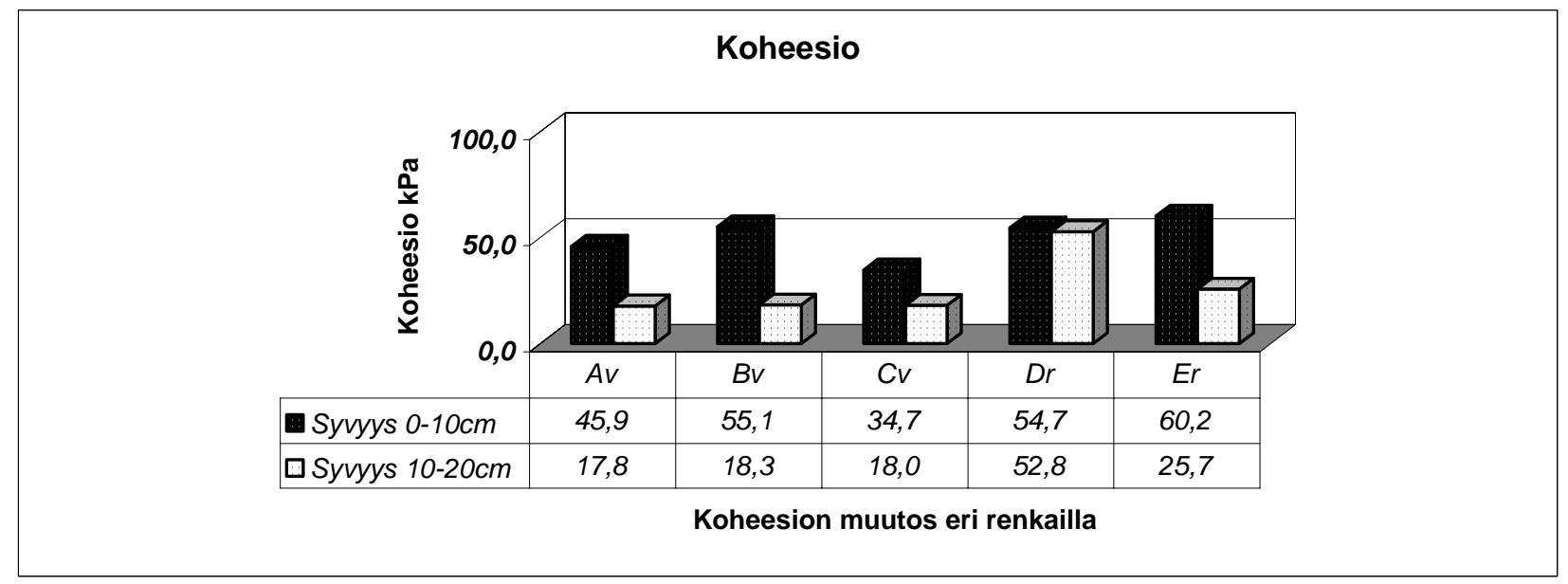

Kuva 5. Vertailurenkaiden aiheuttama koheesion muutos maassa 0-10 ja 10-20 cm syvyydessä. 
Erot CI arvoissa pelto- ja tiepaineiden välillä eivät rengaskohtaisesti olleet merkittäviä. Poikkeus oli elastisin rengas Av, jolla rengaspaineen kasvu aiheutti maassa merkittävän cone-indeksi kasvun. Jäykillä renkailla sensijaan muutokset olivat verraten pieniä. Eri syvyyksillä indeksi muutokset olivat rengaskohtaisesti tarkasteltuna samansuuntaisia, poikeuksena jäykkä ristikudosrengas Dr. Jäykän kulutuspinnan omaava vyörenkaan $\mathrm{Cv}$ kohdalla tiivistyminen oli muista poiketen voimakkainta n. $10 \mathrm{~cm}: n$ syvyydessä. Renkaitten väliset erot olivat sensijaan selvät, jäykät renkaat tiivistivät maata keskimäärin selvästi enemmän.

Mitattaessa renkaan massa aiheuttamaa muutosta koheesion avulla, jäykän pintaosan omaava vyörengas Cv:llä muutos oli selvästi muita pienempi maan pintakerroksessa, kun taas $10-20 \mathrm{~cm}: n$ syvyydessä vyörenkaiden aiheuttama koheesion muutos oli lähes sama

\section{Johtopäätökset}

Eri renkaiden vetovastusten välillä oli selvät erot. Tämä merkitse suurempaa vetovoiman ja vetotehon tarvetta ja polttoaineen kulutuksen lisäystä. Vetovastus riippuu renkaasta ja sen uppoutumisesta alustaansa.

Renkaan rakenteesta aiheutuvat erilaiset ominaisuudet näkyvät myös maassa. Syvä ura merkitsee maan cone-indeksin ja koheesion kasvua, mikä kertoo maan tiivistymisestä.

Maassa tapahtuvat rakenteeliset muutokset tapahtuvat hitaasti pitkän ajan kuluessa ja huomaamattomasti. Oikealla rengasvalinnalla voidaan vaikuttaa maan rakenteeseen.

\section{Kirjallisuus}

Alakukku, L. 2000. Response of annual crops to subsoil compaction in a field experiment on clay soil lasting 17 years. Advances in Geoecology 32: 205-208.

Tijink, F.G.J., Döll,H and Vermeulen, G.D. 1995. Technical and economical feasibility of low ground pressure running gear. Soil Till.Res. 35, pp.99-110

van den Akker, J.J.H., 2003. Prevention of Subsoil Compaction by Using Flotation Tyres or Tracks. International Soil Tillage Research Organisation Conference, Melbourne, pp 1305-1312 